\title{
Opinión
}

\section{El médico en procesos judiciales}

\author{
Grettchen Flores-Sandí
}

\section{Resumen}

La opinión del médico como perito es requerida comúnmente en los procesos judiciales como evidencia. Uno de los fundamentos más importantes de la efectividad de su labor es comprender el proceso y mantener una conducta ética. También los médicos que proveen peritajes deben tener conocimientos actualizados y experiencia en el área en que se pronunciaran. Hay reglas básicas que el perito médico debe siempre tener presente cuando comparece a juicio.

Descriptores: perito médico, ética, peritaje, juicio

\begin{abstract}
Medical expert opinion is commonly required by courts as evidence, and one of the most important fundamentals of effective expert testimony is to understand the process, and to maintain an ethical behavior. Also, physicians who provide expert testimony should have recent and substantive experience and knowledge in the area in which they testify. There are several basic rules the expert witness should consider when testifying.
\end{abstract}

Key words: expert medical witness, ethics, expert testimony, trial.

Con frecuencia, las autoridades judiciales se encuentran ante situaciones complejas cuya solución requiere conocimientos especiales y capacidad técnica, ajenos a su preparación jurídica, ${ }^{1,2} \mathrm{y}$ en tales casos recurren a técnicos en la materia correspondiente, a quienes piden una opinión sobre el punto que se desea aclarar. ${ }^{3-5}$ Además, dado el desarrollo científico actual, la práctica judicial impone cada día con mayor urgencia, la necesidad de recurrir a este tipo de apoyo especializado. ${ }^{6} \mathrm{El}$ medio particularmente empleado para trasmitir y aportar al proceso nociones técnicas y objetos de prueba, se conoce como peritación., ${ }^{2,3}$

En Costa Rica, la intervención pericial del médico en los procesos está sujeta a las normas generales respectivas (artículos 213 a 224 Código Procesal Penal), pero algunas

Departamento de Medicina Legal, Poder Judicial

Correspondencia: Apartado postal: I3238-1000 San José

Correo electronico: gflores68@racsa.co.cr

ISSN 0001-6002/2008/49/1/47-50

Acta Médica Costarricense, (C2008

Colegio de Médicos y Cirujanos normas desperdigadas se refieren en concreto a la pericia médica (artículo 85 Incapacidad sobreviniente, artículo 86 Internación para observación, artículo 87 Examen mental obligatorio, artículo $88 \mathrm{El}$ imputado como objeto de prueba, artículo 191 Levantamiento e identificación de cadáveres, artículo 221 Peritajes especiales, artículo 350 Dictamen Pericial). ${ }^{2}$

Si bien en el campo médico la mayoría de las veces quienes realizan el peritaje son médicos legistas, también existe posibilidad de que el proceso requiera de otros médicos especialistas, ya sea que: a - hayan actuado como interconsultores del Departamento de Medicina Legal (en la actualidad este cuenta con la posibilidad de interconsulta en Anatomía Patológica, Cardiología, Ginecología y Obstetricia, Medicina Interna, Neumología, Oftalmología, Ortopedia y Traumatología, Otorrinolaringología, Radiología e Imágenes Médicas, Psiquiatría), b - actúen a solicitud de la autoridad judicial cuando este Departamento no cuente con especialistas interconsultores en un campo específico (tal sería el caso de un médico especialista en un área diferente de las mencionadas), c- la autoridad judicial estime necesario nombrar uno o más peritos nuevos, de oficio o a petición de alguna de las partes, según la importancia del caso, para que examinen, amplíen o repitan el peritaje.

Las áreas más comunes en que se requiere un peritaje médico son lesiones personales, responsabilidad profesional y procesos laborales. ${ }^{7,8} \mathrm{El}$ peritaje médico es un medio revestido de la forma probatoria legal, que da respuesta a la duda científica requerida, y cuyo pronunciamiento genera inevitable y necesariamente consecuencias jurídicas. Este concepto está en relación con el ser humano y a su salud entendida no solo bajo el contexto de la definición de la Organización Mundial de la Salud, sino adicionalmente a la condición psicofísica que está al servicio de la vida y la libertad de las personas. ${ }^{7}$ En este sentido, junto al deber del médico de mantener la vida debe aparejarse otro valor igualmente importante, como lo es la justicia. ${ }^{9}$

Sin embargo, uno de las fundamentos más importantes de la efectividad del peritaje es no temer al proceso $\mathrm{y}$ comprender no solo su papel de experto en proveer evidencia, sino también las reglas complejas bajo las cuales debe actuar como perito, proveyendo información basada en evidencia científica (basada en la bibliografía) además de su experiencia clínica. $^{1,4-5,8,10-11}$ 
El término evidencia tiene significado diferente en derecho y medicina. En derecho, evidencia es material o testimonio que es admitido en corte. En medicina, se refiere a los datos obtenidos mediante de la investigación científica, cuya calidad está definida por la metodología empleada en la investigación. En derecho existen reglas complejas que restringen el tipo de evidencia que puede ser presentado en un proceso judicial; estas reglas aspiran a excluir evidencia no confiable, irrelevante o engañosa e incluir evidencia que tiene la máxima probabilidad de ser verdadera. ${ }^{4,12}$

En general, los testigos pueden solo dar evidencia real. Un perito, sin embargo, debe cumplir con formación actualizada y experiencia en su campo y poseer suficientes conocimientos jurídicos que le permitan transmitir de manera clara y comprensible sus conclusiones a los profesionales del derecho ${ }^{8,10,13}$ (Cuadro 1), por lo que es permitido para ofrecer su opinión como evidencia. ${ }^{4}$

Si bien, en el proceso, tanto testigos como peritos son tratados con justicia y con respeto, ${ }^{1}$ existen diferencias entre un perito y un testigo, aunque este último tenga experiencia clínica. ${ }^{3,14}$ El sencillo acto del médico de ser testigo, es muy complejo. ${ }^{15} \mathrm{Al}$ respecto: a. El testigo no puede más que consignar un hecho dado a cuya realización ha asistido; el perito, en cambio, puede inducir lo ocurrido y la significación, siendo como una especie de jurado, ya que la opinión que emite debe sustentarse o basarse en las adquisiciones de la ciencia, técnica o por su experiencia. b. El testigo declara sobre hechos pasados o presentes que percibió antes del proceso, en cambio, el perito lo hace sobre hechos pasados, presentes o futuros, percibidos durante el proceso en virtud del encargo judicial. c. Los acontecimientos procesales determinan que una persona sea testigo o no, y que haya de tener una relación histórica con el asunto de que se trate, el perito está a disposición del juez y de que este lo seleccione a discreción ya que el interés al escoger los peritos es saber si tiene los conocimientos que se desean. d. Es improcedente que un testimonio verse únicamente sobre el conocimiento que el testigo tiene de principios abstractos, en cambio el perito puede cumplir suficientemente su tarea emitiendo conceptos de está índole sin relacionarlos con el caso que se le presente.

La particular función del perito no tiene como objetivo emitir un diagnóstico para, a través de un tratamiento, conseguir la restitución de la salud del paciente, sino la de proporcionar a la autoridad judicial una información que le permita aplicar justicia. $^{8}$ De ahí que en el peritaje el procedimiento ético se torna extremadamente importante al estar ligado al campo del derecho, en el cual las normas y deberes morales son más claros a raíz de la íntima unión entre lo moral y lo jurídico. ${ }^{16}$

En el peritaje médico deben añadirse una serie de normas a los principios bioéticos que presiden toda actuación médica: ${ }^{8,13,14}$

1. Honestidad: permanecerá ajeno a cualquier interés espurio en las evaluaciones que se le encomienden.

2. Imparcialidad: expresará sus opiniones científicas prescindiendo de cualquier implicación afectiva sobre los hechos valorados, o sobre cualquiera de las partes contrapuestas en el procedimiento, realizando su valoración con independencia de las consecuencias jurídicas y sociales que puedan derivar de ella.

3. Objetividad: fundamental para la interpretación de las pruebas y resultados obtenidos, sin atender a posibles prejuicios o condicionantes que pueden derivar de los propios hechos o de las circunstancias particulares del caso.

4. Prudencia: no asumirá verdades absolutas, a través del conocimiento de las propias limitaciones, atendiendo a

\begin{tabular}{|c|l|}
\hline \multicolumn{1}{|c|}{ Cuadro 1. Características de un perito modelo } \\
\hline \multirow{2}{*}{ Efectivo } & $\begin{array}{l}\text { - Tiene buena destreza de comunicación } \\
\text { - Es hábil en foros de preguntas y respuestas. } \\
\text { - Tiene un proceder apropiado en la sala de juicio. }\end{array}$ \\
\hline Ético & $\begin{array}{l}\text { - Tiene integridad científica. } \\
\text { - Protege su objetividad. } \\
\text { - Mantiene relaciones profesionales apropiadas con otros participantes. } \\
\text { - Diferencia entre opiniones personales y datos científicos. }\end{array}$ \\
\hline Experto & $\begin{array}{l}\text {-Tiene entrenamiento especializado, certificación apropiada y experiencia profesional: formación } \\
\text { y enseñanza, investigación, experiencia clínica y práctica y publicaciones. } \\
\text {-Tiene completo conocimiento del tema del caso y educación médica continua relevante apropiada. } \\
\text {-Tiene completo conocimiento de los datos del caso. }\end{array}$ \\
\hline Seguro & $\begin{array}{l}\text { - Tiene conocimiento de los procedimientos de la sala de juicio. } \\
\text { - Está preparado para el interrogatorio. } \\
\text { - Es claro en sus opiniones y sus fundamentos. }\end{array}$ \\
\hline
\end{tabular}


que la calidad mayor que debe tener el perito es la noción exacta de lo que sabe y de lo que ignora.

5. Reflexión y juicio: racionalizará los hallazgos razonando de manera lógica sobre ellos, simplificando los problemas que pueden plantearse y jerarquizando lo principal sobre lo accesorio, hasta alcanzar las conclusiones válidas.

6. Veracidad: empleará un método que permita contrastar las conclusiones científicamente obtenidas, debiendo constituirse este principio de veracidad como uno de los soportes primordiales que guíe la prueba pericial.

Por otro lado, el perito puede: aclarar, ilustrar, complementar, dar opiniones sobre su ciencia, pero no pronunciarse sobre aspectos netamente jurídicos; ${ }^{6}$ de hecho, sus opiniones son muy dependientes de las preguntas que hacen los abogados. ${ }^{8} \mathrm{Al}$ respecto, diversos autores han señalado reglas básicas que un perito siempre debe tener en cuenta en la comparecencia a juicio ${ }^{4,6,10,17,18}$ y que es posible resumir de la siguiente manera:

1. Decir siempre la verdad.

2. Hablar fuerte y responder todas las preguntas verbalmente.

3. Ser cortés y profesional, aunque firme y seguro.

4. Contestar siempre las preguntas que le son hechas y evitar ser obstructivo. Evitar términos técnicos, explicar las cosas tan simple como sea posible, utilizar ejemplos cuando sea factible, no ofrecer información que no sea directamente relevante a la pregunta planteada. Utilizar cuadros, gráficos o material audiovisual si es necesario, en especial si puede ayudar al tribunal a entender.

5. Si cree que ha sido mal interpretado, sentirse libre de aclarar o ampliar sobre algún punto, pero mantener su respuesta dirigida a la pregunta.

6. No suponer si no sabe la respuesta, decir que no la sabe. Evitar frases como "pienso" y "supongo". No debe ayudar al abogado a elaborar la pregunta, pero si esta es incontestable o incorrecta, indicar el problema, si puede hacerlo.

7. No permitir que pongan palabras en su boca; escuchar cuidadosamente lo que se le pregunta.

8. Mantenerse sereno, no ser polémico, pero defender sus afirmaciones si son puestas a prueba.

9. No distraerse por los argumentos y objeciones entre abogados. Si hay una objeción antes o a la mitad de una respuesta, dejar de hablar y esperar que el juez se dirija a él para continuar. Estar seguro de terminar las respuestas.

10. Mostrar respeto apropiado para el juez o tribunal, abogados y el proceso. Siempre ponerse de pie cuando el juez o tribunal entre o salga de la sala de juicios. Hablar directamente al tribunal (o al juez si no hay tribunal).

Es necesario entender que el proceso, hasta tanto no llegue el testimonio del especialista, va a quedar prácticamente paralizado, pues se tratará de una de las principales pruebas, sin la cual no es posible resolver el asunto. ${ }^{3}$ Todo esto, recordando que la ciencia es cambiante y dinámica, de modo que posiblemente el o los peritos no ostenten el último conocimiento científico. Pero si el ejercicio se realiza con seriedad y fundamento, será válido, y este valor será asignado por la autoridad judicial con base en su capacidad para evaluar los hechos, en su sano juicio o capacidad de sana crítica, y dependiendo de las características de la prueba médico-pericial, cuya fuerza radica en un elemento: la calidad (la calidad científica de los medios, términos y enunciados empleados por el perito, la calidad del perito relacionada con sus conocimientos y su experiencia, y la responsabilidad jurídica del ejercicio que realiza como perito). ${ }^{6-7}$

Además, la participación del médico como perito, puede ser una experiencia estimulante, agradable, educativa $\mathrm{y}$ profesionalmente recompensadora, porque a causa de sus requerimientos, el médico aprende mucho acerca de su propia disciplina y de cómo su saber es usado en el sistema legal. ${ }^{10}$

La participación del médico como perito en el proceso constituye -en tanto opinión experta- una práctica inherente al quehacer médico, no ajena a la docencia, la investigación y la practica clínica. Y aunque el contexto donde ocurre no es el habitual para el médico, no le debe representar una condición de inseguridad infundada, sino un estímulo para su mejoramiento continuo.

\section{Referencias}

1. Butler-Sloss E, Hall A. Expert witnesses, courts and the law. J R Soc Med. 2002; 95: 431-434.

2. Rojas JD. La pericia médica ( noción y contenido). Med leg Costa Rica 1999; 16: 52-58.

3. Cárdenas LM, Becerra AM. La prueba. U.S. Inter-Affairs. Recuperado el 10 de julio de 2007 en http://www.interamericanusa.com/articulos/ Auditoria/Rol-Cont-2.htm

4. Ryan M. The adversarial court system and the expert medical witness: 'The truth the whole truth and nothing but the truth?' Emerg Med 2003; 15: 283-288

5. Vinen J. The problem facing the expert medical witness: Does the tail wag the dog? Emerg Med 2003 Jun;15:213-4

6. Franco E. La necropsia como peritazgo médico. Revista Médico-Legal on-line. 2000; 1. Disponible en www.medicolegal.com.co/ediciones/1_ 2000/act_med_leg_5.htm

7. Castillo N. Peritazgos Médicos. En: Guzmán Mora F, Franco Delgadillo E, Rosselli Cock DS. La práctica de la medicina y la ley. Colombia: Biblioteca Juridica Dike; 1999 p 331-338.

8. Schofferman J. Opinions and Testimony of Expert Witnesses and Independent Medical Evaluators. Pain Med 2007; 8(4): 376-382 
9. Piga A. Ética en la pericia médico legal. Méd leg Costa Rica 2000, 17:0708

10. Eaton DL, Kalman D. Scientists in the Courtroom: Basic Pointers for the Expert Scientific Witness. Environ Health Perspect 1994;102:668672

11. Castro JD. La responsabilidad penal y civil del perito médico. Med leg Costa Rica 2001, 17:01-04

12. Solano P. El registro médico como prueba en los juicios por mal praxis. Rev Latinoam Derecho Médico y Medicina Legal 2001; 6(1):57-72

13. González J, Rapún A, Altisent R, Irigoyen J. Principios éticos y legales en la práctica pericial psiquiátrica. Ethical and legal principles at the psychiatric expert practice. Cuad Med Forense 2005; 11(42):275-285
14. Rich BA. The Treating Physician as Expert Witness: Ethical and Pragmatic Considerations. Pain Med 2006; 7(5); 460-463.

15. Pareta I. O médico na condição de testemunha. J Vasc $\mathrm{Br}$ 2003;2:266.

16. Da Rocha J. Comportamento ético em perícia judicial. Revista Engenharia 1998; 530. Disponible en www.brasilengenharia.com.br www.etica.eng.br/uploads/etica_perito_judicial.pdf

17. Friston M. Roles and responsibilities of medical expert witnesses. BMJ 2005;331:305-306.

18. Wise J. Where expert witnesses fear to tread. BMJ 2006;332:500-501

\section{Costa Rica en el exterior}

\section{Diversidad de los genes cagAy vacA de Helicobacter pylori en Costa Rica: su relación con gastritis atrófica y cáncer gástrico.}

Con SA, Takeucho H, Valerín AL, Con-Wong R, Con-Chin GR, Con-Chin VG, Nishioka M, Mena F, Brenes F, Yasuda $\mathrm{N}$, Araki K, Sugiera T.

Helicobacter. 2007 Oct;12(5):547-52.

Introducción: En Costa Rica no se han reportado asociaciones entre la diversidad de genes de Helicobacter pylori y cáncer gástrico, a pesar de ser uno de los países con una incidencia muy alta y gran mortalidad por esta neoplasia en el mundo. El objetivo de este estudio fue determinar la prevalencia de los genes cagA y vacA de $\mathrm{H}$. pylori y de investigar si se correlacionaban con gastritis atrófica (GA) y cáncer gástrico en Costa Rica.

Material y métodos: Las muestras de DNA genómico de 104 pacientes fueron divididas en 2 grupos: gastritis no atrófica (n: 68), y gastritis atrófica (n:36) y luego fueron sometidas a pruebas de PCR buscando fenotipos de vacA y cagA y los resultados se correlacionaron con los datos clínicos. Extracciones totales de DNA de tejidos gástricos de 25 pacientes con cáncer gástrico infectados con $\mathrm{H}$. pylori se utilizaron para efectos comparativos.

Resultados: Se detectó la presencia de cagA en $75.3 \%$, de vacA s $1 \mathrm{~b}$ en $75.3 \%$ y de vac A $\mathrm{m} 1$ en $74.2 \%$ y colonización por cepas con diferentes genotipos de vacA en el mismo estómago en $9.7 \%$ de los pacientes. Una vez ajustadas por edad y sexo, vacA s1b y vacA $\mathrm{m} 1$ se asociaban con $\mathrm{GC}$ mientras solo vacA $\mathrm{m} 1$ estaban significativamente asociadas con GA. Hubo una tendencia de asociación entre cagA y vacA s1b y GA.

Conclusiones: El estado de prevalencia de los genes cagA y vacA $(\mathrm{s} 1 / \mathrm{m} 1)$ en Costa Rica pareciera concordar con lo que se encuentra en Europa/Norte América y los países del este de Asia y ambos cagA y vacA parecieran tener relevancia clínica en nuestro país.

\section{Farmacocinética y farmacodinamia de gatifloxacina en niños con otitis medica recurrente: aplicación de un muestreo limitado durante el desarrollo clínico.}

Christopher M. Rubino, Paul Ambrose, Brenda Cirincione, Adriano Arguedas, Lawrence Sher, Eduardo López, Xavier Saénz Llorens y Dennos M. Grasela

Diagnostic Microbiology and Infectious Diseases 2007;59:67-74

\section{Resumen}

La gatifloxacina es un antibiótico de la familia de las fluorquinolonas de 4ta generación que ha sido estudiada para el tratamiento de niños e infantes con otitis media. El motivo de esta publicación fue analizar el tiempo de exposición de este medicamento en niños relación con la población adulta y examinar la relación entre la exposición a la gatifloxacina y la respuesta terapéutica en niños con otitis media o que fueran considerados fallas terapéuticas. La población estudiada incluyó un total de 187 niños que participaron en un estudio abierto, multicéntrico, no comparativo en el cual se utilizó la gatifloxacina a una dosis de $10 \mathrm{mg} / \mathrm{Kg}$, una vez al día. El tiempo de exposición a la gatifloxacina fue estimada utilizando una única muestra sanguínea durante el periodo de equilibrio en conjunto con un modelo fármaco estadístico desarrollado utilizando datos pediátricos independientes. La exposición a la gatifloxacina en la población de niños estudiada fue equivalente a la exposición en adultos luego de recibir una dosis diaria de 400mg. De los 41 pacientes en los que se aisló un Streptococcus pneumoniae del oído medio, solo se documento 3 fallas bacteriológicas; no se documentó que existiera ninguna relación entre el radio plasmático fu $\mathrm{AUC}_{0-24}$ : CIM y la respuesta clínica. En conclusión, los métodos farmacocinéticos/farmacodinámicos aplicados en este estudio permitieron estimar el tiempo de exposición a la gatifloxacina utilizando una única muestra por paciente. 